\title{
In silico investigation of ligand-regulated palladium-catalysed formic acid dehydrative decomposition under acidic conditions
}

\author{
Chaoren Shen, ${ }^{* a c}$ Kaiwu Dong, ${ }^{a}$ Zhihong Wei ${ }^{\mathrm{b}}$ and Xinxin Tian*b \\ ${ }^{a}$ Chang-Kung Chuang Institute, Shanghai Key Laboratory of Green Chemistry and Chemical \\ Processes, School of Chemistry and Molecular Engineering, East China Normal University, \\ Shanghai 200062 P. R. China. E-mail: shenchaoren@ gmail.com \\ ${ }^{\mathrm{b}}$ Institute of Molecular Science, Key Laboratory of Materials for Energy Conversion and \\ Storage of Shanxi Province, Shanxi University, Taiyuan 030006, P. R. China. E-mail: \\ tianxx@sxu.edu.cn \\ ${ }^{\mathrm{c}}$ State Key Laboratory for Oxo Synthesis and Selective Oxidation (OSSO), Suzhou Research \\ Institute of LICP, Lanzhou Institute of Chemical Physics (LICP), Chinese Academy of \\ Sciences (CAS), Lanzhou 730000, China
}

\begin{abstract}
In silico investigation of ligand-regulated palladium-catalysed formic acid dehydrative decomposition to carbon monoxide under acidic conditions was conducted. Two types of bidentate tertiary phosphine ligands were selected on the basis of previous experimental study. And the promoting effect of para-toluenesulfonic acid (PTSA) was specifically investigated. The pyridyl group implanted in $\mathrm{py}^{t} \mathrm{bpx}$ ligand is found to mainly contribute on enhancing the activity of palladium catalyst. The PTSA promoter displays specific role for regenerating active species and supressing dehydrogenation during $\mathrm{Pd}-\mathrm{py}^{t} \mathrm{bpx} / \mathrm{Pd}-\mathrm{d}^{t} \mathrm{bpx}$ catalysed dehydration process. CO releasing process catalysed by Pd-dtbpx also facilitated by adding PTSA. According to the mechanism hereby supposed, introducing electron-withdrawing substitution at para-position of pyridyl rings may further improve the dehydrative decomposition activity of Pd-pytbpx.
\end{abstract}

\section{Introduction}

Carbonylation reactions constitute a potent tool to manufacture carboxylic acids and their derivatives both in industry and academic organic synthesis. ${ }^{1-7}$ In general, the proceeding of carbonylation requires the use of toxic carbon monoxide, which thus usually demands certified high pressure reaction vessels. ${ }^{8}$ Therefore, developing non-gaseous CO surrogate for conducting safe and facile-operation carbonylation with stoichiometric amount of $\mathrm{CO}$ in common Pyrex glass vessels (e.g., the two-chamber reactor ${ }^{8}$ and sealed glass tube) is an important and ongoing research topic in the realm of homogenous catalysis. ${ }^{9-15}$ Among these established $\mathrm{CO}$ surrogates, formic acid and its derivatives is one kind of versatile atom- 
economic $\mathrm{C} 1$ source. Different to the decomposition of formic ester or $\mathrm{N}$-formyl imides releasing $\mathrm{CO}$ in the basic conditions for the carbonylation of aryl or alkyl halides, ${ }^{16-18}$ the dehydrative decomposition of $\mathrm{HCOOH}$ to $\mathrm{CO}$ generally depends on the Morgan reaction using excess strong mineral acid (e.g., excess high-concentration sulfuric acid), ${ }^{19}$ which is incompatible to the conditions for most of transition-metal catalysed carbonylation reactions. Moreover, undesired dehydrogenation of $\mathrm{HCOOH}$ to $\mathrm{CO}_{2}$ and $\mathrm{H}_{2}$, which is more thermodynamically favoured, can facilely occur in the presence of various homogenous transition-metal complex catalysts or heterogeneous catalysts and lead to the reduction of unsaturated bonds. ${ }^{20}$ Thus, to avoid this side reaction, acetic anhydride has to be added as the activator for in-situ generating the more active CO source mixed anhydride. ${ }^{21-24}$ In 2018, Beller and co-workers achieved the selective $\mathrm{CO}$ generation directly from $\mathrm{HCOOH}$ under acidic condition by a palladium-catalysed system with bidentate tertiary phosphine ligand bearing pyridyl substituents (py'bpx and pyadbpx), which were derived from 1,2-bis(di-tertbutylphosphino) methylbenzene ( $\mathrm{d}^{t} \mathrm{pbx}$ ) (Figure 1). ${ }^{25}$ The utility of this catalytic system in the autoclave-free hydrocarbonylation of all kinds of alkenes was also demonstrated. ${ }^{25}$

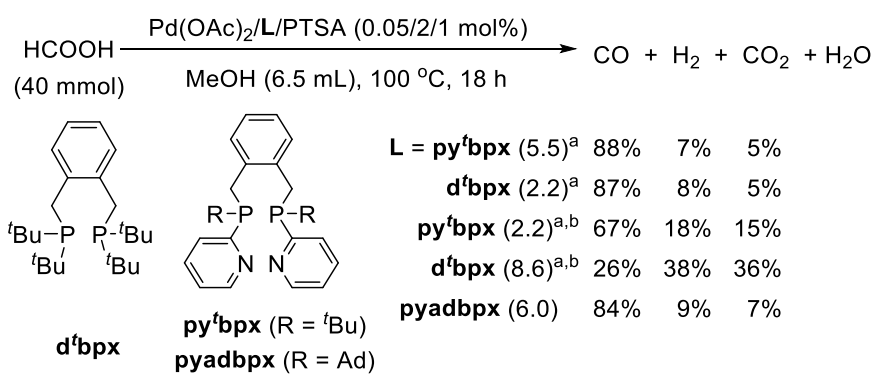

Figure 1. The ligand-regulated palladium-catalysed selective decomposition of $\mathrm{HCOOH}$ to $\mathrm{CO}$. PTSA = para-toluenesulfonic acid. ${ }^{25}$ aMolar percentage of gaseous products and in paratheses are total pressure (unit: bar) after reaction. ${ }^{\text {b} W i t h o u t ~ a d d i n g ~ P T S A . ~ A d ~=~ 1-a d m a n t y l . ~}$

The experimental investigation by Beller et al. disclosed that the activity and selectivity of Pd catalyst to the $\mathrm{HCOOH}$ dehydration was regulated by both the ligand and the acid promoter (Figure 1). The ligand py ${ }^{t} \mathrm{bpx}$ resulted from replacing two tetra-butyl substituents in $\mathrm{d}^{t} \mathrm{bpx}$ with 2-pyridyl groups exhibited significantly higher $\mathrm{CO}$ selectivity than the original $\mathrm{d}^{t} \mathrm{bpx}$ ligand (67\% vs. 26\%). Adding catalytic amount of para-toluenesulfonic acid (PTSA) can improved the CO selectivity, especially for Pd-dtbpx catalytic system (87\% vs. 26\%). Meanwhile, the activity towards dehydration using Pd-py ${ }^{t}$ bpx complex is considerably increased (5.5 bar vs. 2.2 bar) and higher than that of Pd-dtbpx complex (more detailed results see Figure 1 of ref. $25)$. The ligand pyadbpx is obtained by further replacing the tetra-butyl $\left({ }^{t} \mathrm{Bu}\right)$ substituents of py ${ }^{t}$ bpx with bulkier 1-adamantly group (Ad). Pd-pyadbpx catalyst also manifests high activity and selectivity to $\mathrm{HCOOH}$ dehydration, which is comparable to the Pd-pytbpx catalyst. These results indicated the importance of "built-in base" (i.e., 2-pyridyl group) in enhancing the activity and selectivity of palladium catalyst. ${ }^{26}$ In contrast to the promoting effect of such "built- 
in base" on palladium-catalysed hydrocarbonylation of unsaturated hydrocarbons clearly elucidated by the computational survey, ${ }^{26,27}$ the explicit role of ligand bearing "built-in base" in palladium-catalysed $\mathrm{HCOOH}$ dehydration was yet to be disclosed. Considering that the plausibility of in-situ generated methyl formate acting as CO-releasing agent has been experimentally ruled out ${ }^{25}$ (details see Scheme 4 and $\mathrm{S} 1$ of ref. 25), we intended to elucidate the role of acid promoter and basic 2-pyridyl group of the ligand in palladium-catalysed formic acid dehydrative decomposition. By density functional theory-based computation, the difference between the Pd-pytbpx and Pd-dtbpx catalysts on the mechanism of formic acid decomposition was revealed.

\section{Computational method}

All DFT calculations were performed using Gaussian 16 program. ${ }^{28}$ Considering the applicability of meta-generalized gradient approximation (meta-GGA) functional M06 ${ }^{29}$ on homogeneous organometallic thermochemistry, ${ }^{30}$ the M06 functional in conjugation with the def2-SVP basis set ${ }^{31}$ was used for structure optimization. Corresponding frequency calculation using the same method was done to characterize the nature of the optimized structures, i.e., energy minimums without imaginary frequencies or transition states with only one imaginary frequency. Intrinsic reaction coordinate (IRC) was used to check the imaginary model that connects the initial and the final states. In addition, we used M06 in conjugation with the def2TZVP basis set to conduct the self-consistent reaction field (SCRF) single-point calculations based on the M06/def2SVP-optimized geometries by using the SMD solvation model ${ }^{32}$ and methanol as solvent to Gibbs free energies (M06-SCRF/def2-TZVP//M06/def2-SVP). The thermal corrections to Gibbs free energy at $373 \mathrm{~K}$ calculated by the Shermo program ${ }^{33}$ were added to the total electronic energies from the SCRF single-point energy calculations. The corrected Gibbs free energy $(\Delta \mathrm{G})$ at $373 \mathrm{~K}$ were therefore used in the following discussion and comparison.

\section{Results and discussion}

\section{HCOOH dehydration by Pd-py'bpx or Pd-d'bpx (paths A-D)}

Experimental results have demonstrated that the presence of PTSA is critical to the activity and selectivity of Pd-catalysed dehydration of $\mathrm{HCOOH} .{ }^{25}$ Thus, two sets of mechanism with or without the aid of PTSA promoter were considered for this process. A previous study has revealed that the nitrogen atom of the pyridyl ring has a higher proton affinity than the palladium atom in the acidic conditions, ${ }^{26,27}$ similar trend is also found in this study. Therefore, the coordination-unsaturated cationic $\mathrm{Pd}^{0}-\mathrm{py}^{t} \mathrm{bpx}$ complex 1-py ${ }^{t} \mathbf{b p x}$ bearing protonated pyridyl group is regarded as the active species for Pd-pytbpx catalyst and the starting point of reaction

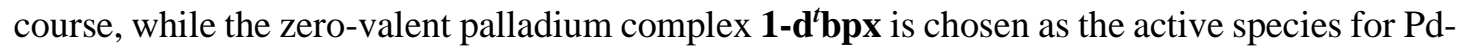
$d^{t}$ bpx catalyst. And the oxidative addition of $\mathrm{HCOOH}$ to $\mathrm{Pd}(0)$ is supposed as the first step. The 


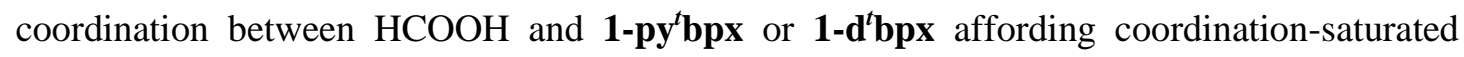
palladium complex is moderately endothermic (2.9-5.3, 7.3-9.5 kcal/mol, respectively). Detailed free-energy changes see Fig. S1 in SI. The plausible coordination of methanol solvent to the $\mathrm{Pd}(0)$ centre is also considered. The coordination of $\mathrm{CH}_{3} \mathrm{OH}$ to 1-py $\mathbf{y}^{\mathbf{t}} \mathbf{b p x}$ is more endothermic $\left(8.9 \mathrm{kcal} / \mathrm{mol}\right.$, Fig. S1) than that of $\mathrm{HCOOH}$, and the structure of $\mathrm{CH}_{3} \mathrm{OH}$ coordinated 1-d $\mathbf{b}$ bpx cannot be located. These results further rationalize the initial active species adopted in this work. Given that $\mathrm{CH}_{3} \mathrm{OH}$ can form complex hydrogen-bonding interaction network with $\mathrm{HCOOH}, \mathrm{PTSA}$ or itself and water by-product is gradually accumulated in the course of $\mathrm{HCOOH}$ dehydration, the explicit solvation of $\mathrm{CH}_{3} \mathrm{OH}$ and $\mathrm{H}_{2} \mathrm{O}$ are omitted to simplify the reaction model and only the implicit solvation of $\mathrm{CH}_{3} \mathrm{OH}$ is considered in this computational investigation.

Fig. 2 illustrated the two plausible paths for $\mathrm{HCOOH}$ dehydration to $\mathrm{CO}$ catalysed by $\mathrm{Pd}$ py ${ }^{t}$ bpx (path $\mathbf{A}$ and $\mathbf{B}$ ). Path $\mathbf{A}$ starts from the C-H activation of $\mathrm{HCOOH}$ by 1-py $\mathbf{y}^{t} \mathbf{b p x}$ ( $\mathrm{HCOOH}$ + 1-py $\mathbf{t}^{t} \mathbf{b p x} \rightarrow$ 2-py ${ }^{t} \mathbf{b p x}$ via TS1-py $\left.\mathbf{y}^{t} \mathbf{b p x}\right)$ followed by the intramolecular dehydration facilitated by the pyridinium group (2-py $\mathbf{y}^{t} \mathbf{b p x} \rightarrow \mathbf{3}-\mathbf{p y} \mathbf{y}^{t} \mathbf{b} \mathbf{p} \mathbf{x}+\mathrm{H}_{2} \mathrm{O}$ via TS2-py $\left.\mathbf{y}^{t} \mathbf{b p x}\right)$. The first step is endergonic by $10.3 \mathrm{kcal} / \mathrm{mol}$, with a barrier of $12.3 \mathrm{kcal} / \mathrm{mol}$. The generated $\mathbf{2 - p \mathbf { y } ^ { t } \mathbf { b p x }}$ has an intramolecular hydrogen-bonding between the $\mathrm{OH}$ of $\mathrm{COOH}$ group and the proton attaching to the nitrogen atom of pyridyl group. The directly combination of $\mathrm{OH}$ and $(\mathrm{N}-) \mathrm{H}$ and subsequent delivering one $\mathrm{H}_{2} \mathrm{O}$ molecule has low barrier of $11.6 \mathrm{kcal} / \mathrm{mol}$ and is highly exergonic by $17.6 \mathrm{kcal} / \mathrm{mol}$. Considering the co-existence of PTSA, $\mathrm{HCOOH}$ and $\mathrm{CH}_{3} \mathrm{OH}$ in the catalytic system, PTSA-, $\mathrm{HCOOH}-$ or $\mathrm{CH}_{3} \mathrm{OH}$-involved processes are also investigated. Oppositely, inserting $\mathrm{HCOOH}$, PTSA or $\mathrm{MeOH}$ into this intramolecular hydrogen bond and forming a seven-membered ring connected by two hydrogen bonds is thermodynamically unbeneficial (detailed result see Fig. S2 in SI). We therefore suppose that the dehydration step has no PTSA, $\mathrm{MeOH}$ or the second $\mathrm{HCOOH}$ molecule involved. Afterwards, the carbonyl palladium hydride complex $\mathbf{3}-\mathbf{p y}^{t} \mathbf{b p x}$ can directly release $\mathrm{CO}$ with the formation of palladium hydride complex $\mathbf{4} \mathbf{b}$-py $\mathbf{y}^{t} \mathbf{b p x}$ followed by the direct hydrogen migration of $\mathbf{4} \mathbf{b}-\mathbf{p} \mathbf{y}^{t} \mathbf{b p x}$ to recover

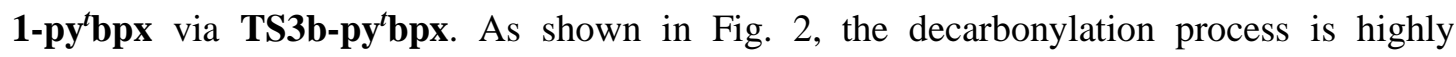
endergonic by $29.7 \mathrm{kcal} / \mathrm{mol}$, but the hydrogen migration is almost barrierless. With the assistance of PTSA, $\mathrm{HCOOH}$ or $\mathrm{CH}_{3} \mathrm{OH}$, it is found that although the ligand exchange with

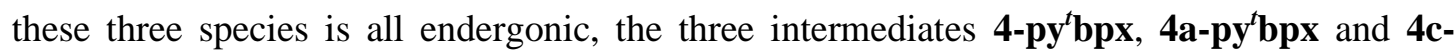
$\mathbf{p y}^{t} \mathbf{b p x}$ are all thermodynamically more stable than the $\mathbf{4} \mathbf{b}-\mathbf{p} \mathbf{y}^{t} \mathbf{b p x}$ (1.5, 4.1, 4.6 vs. 22.4 $\mathrm{kcal} / \mathrm{mol}$ ). And the apparent Gibbs free energies of TS3-py ${ }^{t} \mathbf{b p x}$ and TS3a-py $\mathbf{y}^{t} \mathbf{b p x}$ are lower than that of TS3b-py ${ }^{t} \mathbf{b p x}(15.5,16.1$ vs. $20.3 \mathrm{kcal} / \mathrm{mol})$, while the Gibbs free energy of TS3cpy $^{t} \mathbf{b p x}$ is much higher than that of $\mathbf{T S 3 b}-\mathbf{p y}^{t} \mathbf{b p x}$ ( $\left.34.3 \mathrm{vs.} 20.3 \mathrm{kcal} / \mathrm{mol}\right)$. Therefore, we can deduce that PTSA- and $\mathrm{HCOOH}$-assisted hydrogen migration processes are both possible. The detailed processes are compared in Fig.3. It is noticed that the further protonation of $\mathbf{3}-\mathbf{p y} \mathbf{y}^{\mathbf{t}} \mathbf{b p \mathbf { p }}$ by PTSA and the following CO dissociation as well as the 1-py $\mathbf{y}^{\mathbf{t}} \mathbf{b p x}$ regeneration steps are more 
thermodynamically beneficial than that of by $\mathrm{HCOOH}$. Also, the Gibbs free energy of TS3$\mathbf{p y}^{t} \mathbf{b p x}$ is $0.6 \mathrm{kcal} / \mathrm{mol}$ lower than that of TS3a-py $\mathbf{y}^{t} \mathbf{b p x}$. All these suggest that adding PTSA indeed facilitate the $\mathrm{CO}$ releasing and catalyst regeneration.

Path $\mathbf{B}$ also starts from the C-H activation of $\mathrm{HCOOH}$ by $\mathbf{1}-\mathbf{p} \mathbf{y}^{t} \mathbf{b p x}\left(\mathrm{HCOOH}+\mathbf{1}-\mathbf{p y} \mathbf{y}^{t} \mathbf{b p x} \rightarrow\right.$ 2a-py $\mathbf{y}^{t} \mathbf{b p x}$ via TS1a-py $\mathbf{y}^{t} \mathbf{b p x}$ ). Differently, the intramolecular hydrogen-bonding in TS1a$\mathbf{p y}^{t} \mathbf{b p x}$ and 2a-py $\mathbf{y}^{t} \mathbf{b p x}$ lies between the oxygen atom of carbonyl group and the H-N moiety of pyridinium group. When $\mathbf{2} \mathbf{a}-\mathbf{p} \mathbf{y}^{t} \mathbf{b p x}$ undergoes the intermolecular dehydration to $\mathbf{3 a - p \mathbf { y } ^ { t } \mathbf { b p x }}$ facilitated by PTSA or $\mathrm{HCOOH}$ as the proton shuttle, the barrier via TS2a-py $\mathbf{t}^{t} \mathbf{b p x}$ /TS2b$\mathbf{p y}^{t} \mathbf{b p x}$ containing eight-membered proton transfer ring is lower than that via TS2d-

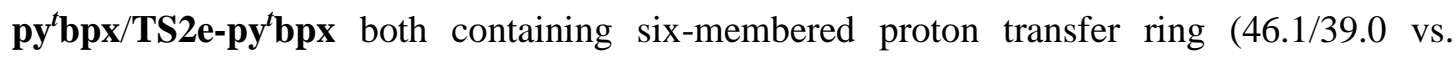
49.5/48.3 kcal/mol). The afforded $\mathrm{H}_{2} \mathrm{O}$ comes from the combination of $\mathrm{OH}$ group of $\mathrm{COOH}$ and the proton of acid, while the hydrogen atom binding to Pd centre is transferred to the oxygen terminal of acid. In the absence of both PTSA and $\mathrm{HCOOH}$, the subsequent intramolecular dehydration of 2a-py $\mathbf{y}^{t} \mathbf{b p x}$ squeezing out one $\mathrm{H}_{2} \mathrm{O}$ molecule via TS2c-py ${ }^{t} \mathbf{b p x}$ also needs to surmount the energy barrier of high as $39.9 \mathrm{kcal} / \mathrm{mol}$. The formed $\mathrm{H}_{2} \mathrm{O}$ comes from the combination between the $\mathrm{OH}$ group of $\mathrm{COOH}$ and the $\mathrm{H}$ atom connecting to Pd. Finally, 1-

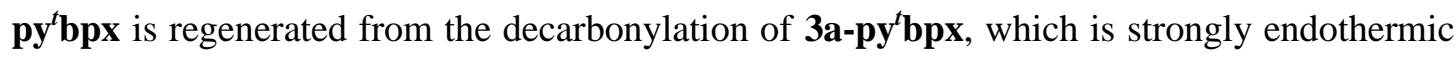
by $19.8 \mathrm{kcal} / \mathrm{mol}$. It can be seen that $\mathrm{HCOOH}$-assisted dehydration via TS2b-py $\mathbf{t}^{\mathbf{t}} \mathbf{b p x}$ has close barrier with the direct dehydration process via TS2c-py ${ }^{t} \mathbf{b p x}$ (39.0 vs. $\left.39.9 \mathrm{kcal} / \mathrm{mol}\right)$, while PTSA-mediated dehydration has higher barrier $(46.1 \mathrm{kcal} / \mathrm{mol})$.

The obtained free-energy results about path $\mathbf{A}$ and $\mathbf{B}$ revealed the dehydration step (2-py ${ }^{t} \mathbf{b p x}$ $\rightarrow$ TS2-py ${ }^{t} \mathbf{b p x}$ and $\left.2 \mathbf{a}-\mathbf{p y} \mathbf{y}^{t} \mathbf{b p x} \rightarrow \mathbf{T S 2}^{\mathbf{b}} \mathbf{b}-\mathbf{p} \mathbf{y}^{t} \mathbf{b p x}\right)$ is the rate-degerming step in both paths. However, the free energy of $\mathbf{T S 2}^{-\mathbf{p y}} \mathbf{y}^{t} \mathbf{b p x}$ is evidently much lower than that of $\mathbf{T S 2} \mathbf{b}-\mathbf{p y} \mathbf{y}^{t} \mathbf{b p x}$ ( 21.9 vs. $48.7 \mathrm{kcal} / \mathrm{mol}$ ). Suggesting that the protonated pyridyl group directly attends the dehydration process by contributing its own proton can drastically reduce the apparent activation energy of $\mathrm{HCOOH}$ dehydration to $\mathrm{CO}$. Moreover, in the absent of PTSA, $\mathrm{HCOOH}$ assisted CO releasing and catalyst regeneration process is favourable. Adding PTSA can considerably promote the $\mathrm{CO}$ dissociation from intermediate $\mathbf{3}-\mathbf{p y} \mathbf{y}^{t} \mathbf{b p x}$ and the regeneration of active species $\mathbf{1}-\mathbf{p y} \mathbf{y}^{\mathbf{t}} \mathbf{b p x}$. 


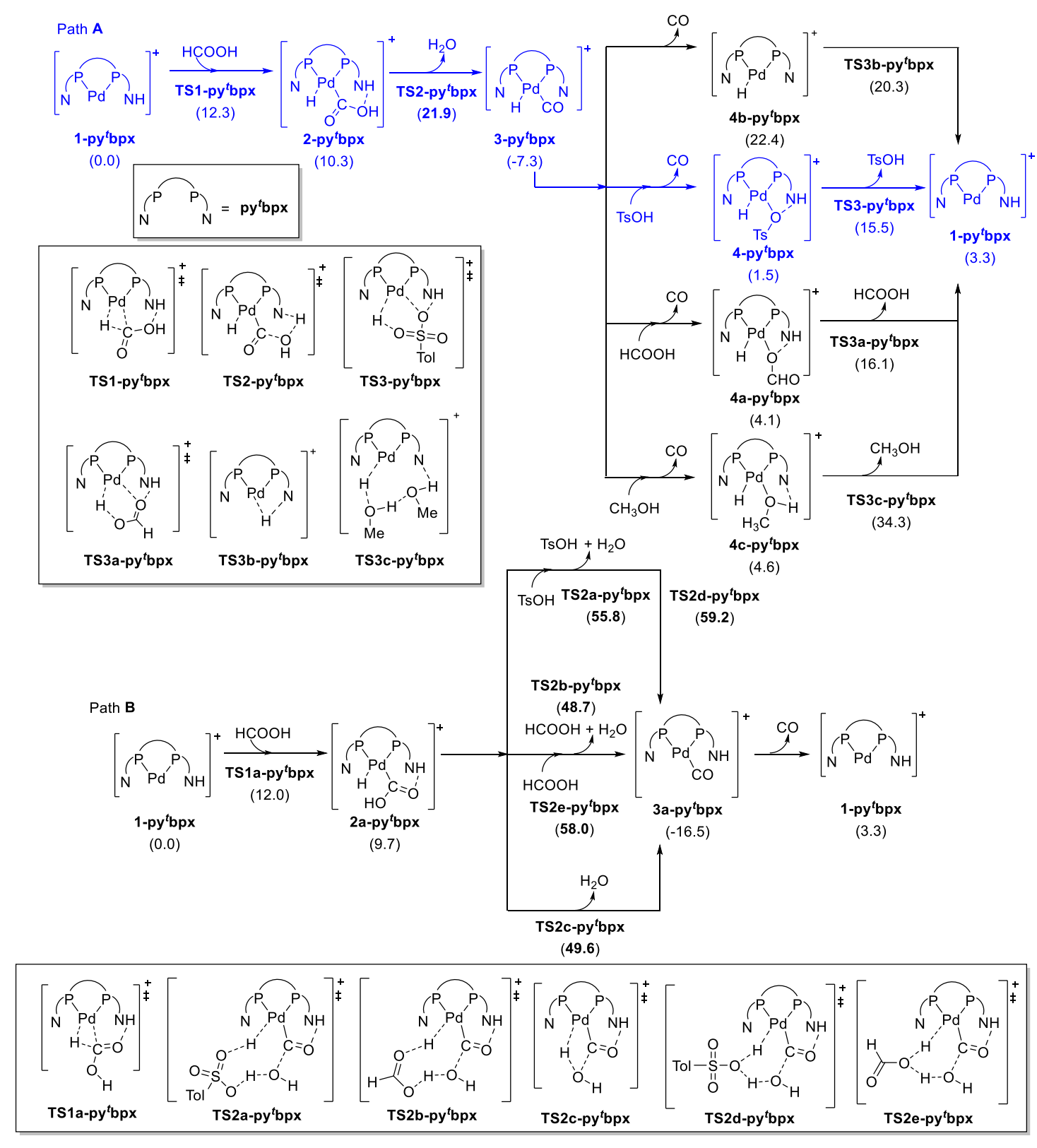

Figure 2. The dehydration of $\mathrm{HCOOH}$ catalysed by $\mathrm{Pd}-\mathrm{py}^{t} \mathrm{bpx}$ (path $\mathbf{A}$ and $\mathbf{B}$ ).

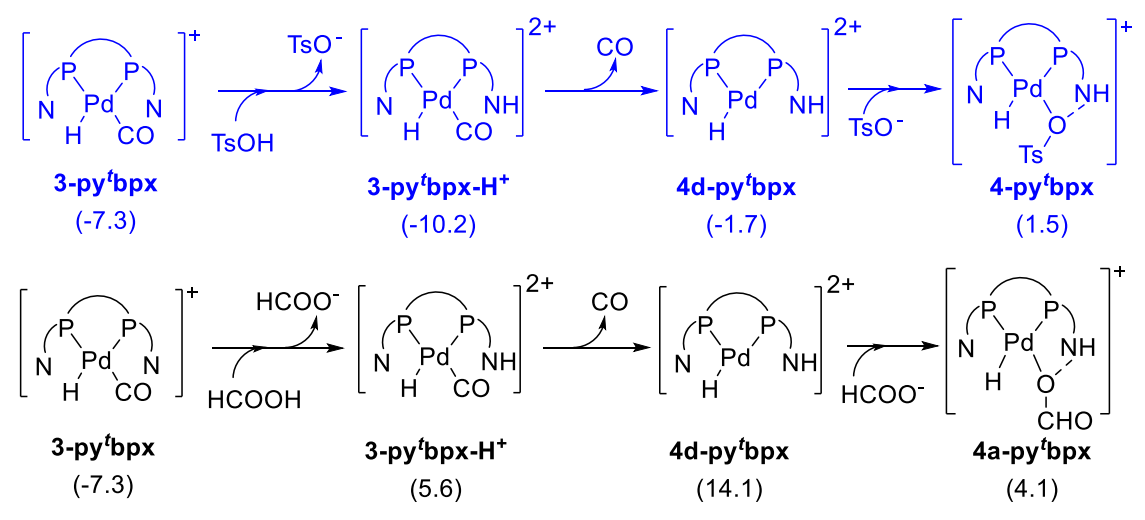


Figure 3 Detailed process and free-energy changes for the CO dissociation and ligand exchange of $\mathbf{3}-\mathbf{p y} \mathbf{y}^{t} \mathbf{b p x}$ to $\mathbf{4}-\mathbf{p y} \mathbf{y}^{t} \mathbf{b p x}$ and $\mathbf{4} \mathbf{a}^{-p y^{t}} \mathbf{b p x}$ respectively by PTSA and $\mathrm{HCOOH}$.

Figure 4 displays the two plausible paths (path $\mathbf{C}$ and $\mathbf{D}$ ) for $\mathrm{HCOOH}$ dehydration catalysed by Pd-d'bpx (1-d $\left.\mathbf{d}^{t} \mathbf{b p x}\right)$. Similar to the dehydration by Pd-py $\mathrm{y}^{t} \mathrm{bpx}$, path $\mathbf{C}$ and $\mathbf{D}$ are also initiated

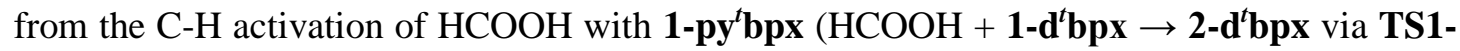
$\mathbf{d}^{t} \mathbf{b p x}$ ). The process is endergonic by $12.1 \mathrm{kcal} / \mathrm{mol}$, with a barrier of $14.9 \mathrm{kcal} / \mathrm{mol}$. The further transformation of 2-d $\mathbf{d}^{t} \mathbf{b p x}$ has two alternatives: i) the acid directly-participated intermolecular

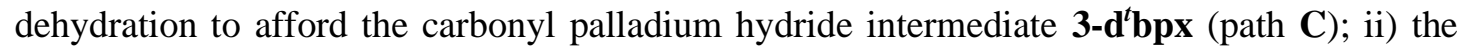
acid-assisted intermolecular dehydration or direct intramolecular dehydration to give the

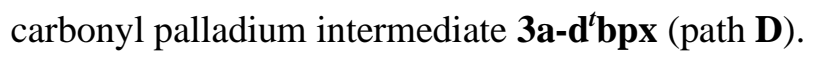

In path $\mathbf{C}$, the PTSA-mediated intermolecular dehydration via TS2-d $\mathbf{d}^{\mathbf{b} p \mathbf{p}}$ exhibited significantly lower energy barrier than the $\mathrm{HCOOH}$-mediated process via TS2a-d ${ }^{t} \mathbf{b p x}$ (11.7 vs. $17.6 \mathrm{kcal} / \mathrm{mol}$ ). The former process to $\mathbf{3 - d ^ { t }} \mathbf{b p x}$ is much more exothermic than the latter one (30.6 vs. $-14.8 \mathrm{kcal} / \mathrm{mol}$ ). Thus, the transformation from $\mathbf{2}-\mathbf{d}^{t} \mathbf{b p x}$ to $\mathbf{3}-\mathbf{d}^{t} \mathbf{b p x}$ via $\mathbf{T S 2} 2-\mathbf{d}^{t} \mathbf{b p x}$ is both kinetically and thermodynamically more favoured. For the PTSA- and $\mathrm{HCOOH}$-attended

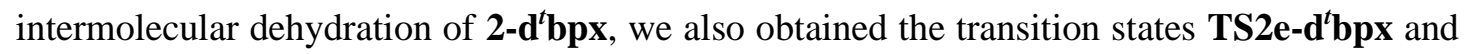
TS2f-d ${ }^{t}$ bpx bearing six-membered ring motif for transferring proton from the acid onto the $\mathrm{OH}$ group. But both have much higher free energy than TS2-d'bpx and TS2a-d $\mathbf{d}^{t} \mathbf{b p x}$, respectively (details see Fig. S3 in SI). Intermediate 4-d $\mathbf{d}^{t} \mathbf{b p x}$ generated from the ligand exchange between

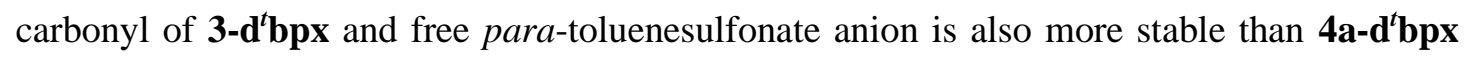
afforded from the ligand exchange between carbonyl ligand of $\mathbf{3}-\mathbf{d}^{t} \mathbf{b p x}$ and free formate anion.

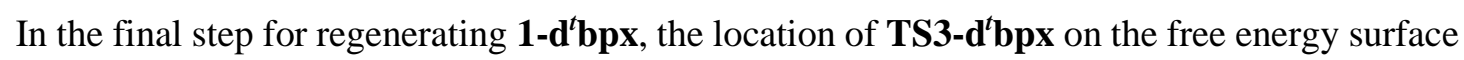

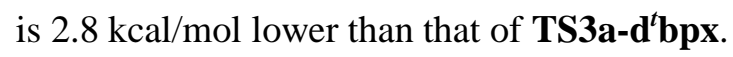

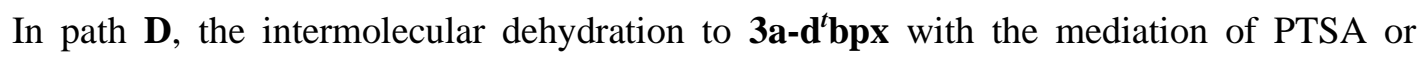
HCOOH as proton shuttle via TS2b-d $\mathbf{d}^{t} \mathbf{b p x}$ and $\mathbf{T S 2} \mathbf{c}-\mathbf{d}^{t} \mathbf{b p x}$ both bearing eight-membered proton transfer chain requires to overcome the energy barrier of 13.8 or $18.7 \mathrm{kcal} / \mathrm{mol}$. In

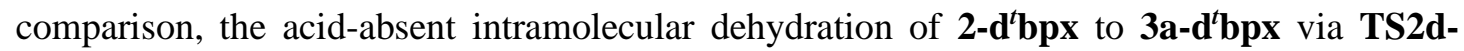
$\mathbf{d}^{t} \mathbf{b p x}$ requires to overcome the energy barrier as high as $37.8 \mathrm{kcal} / \mathrm{mol}$. Moreover, the

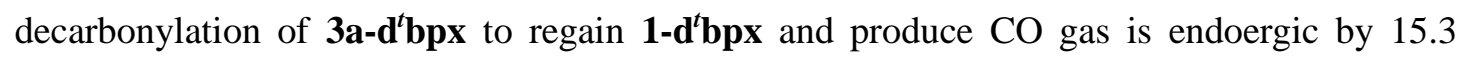
$\mathrm{kcal} / \mathrm{mol}$. Although the acid-mediated intermolecular dehydration in path $\mathbf{D}$ has moderate energy barrier, the lower free energy of TS2-d $\mathbf{d}^{t} \mathbf{b p x}$ than $\mathbf{T S 2} \mathbf{b}-\mathbf{d}^{t} \mathbf{b p x}$ by $2.1 \mathrm{kcal} / \mathrm{mol}$ suggests that PTSA-mediated path $\mathbf{C}$ is more advantageous than PTSA-mediated path D. However, in the absent of PTSA, the $\mathrm{HCOOH}$-assisted path $\mathbf{C}$ is kinetically favourable than the $\mathrm{HCOOH}$ assisted or non-assisted path D (29.7 vs. $30.8 / 49.9 \mathrm{kcal} / \mathrm{mol})$. 


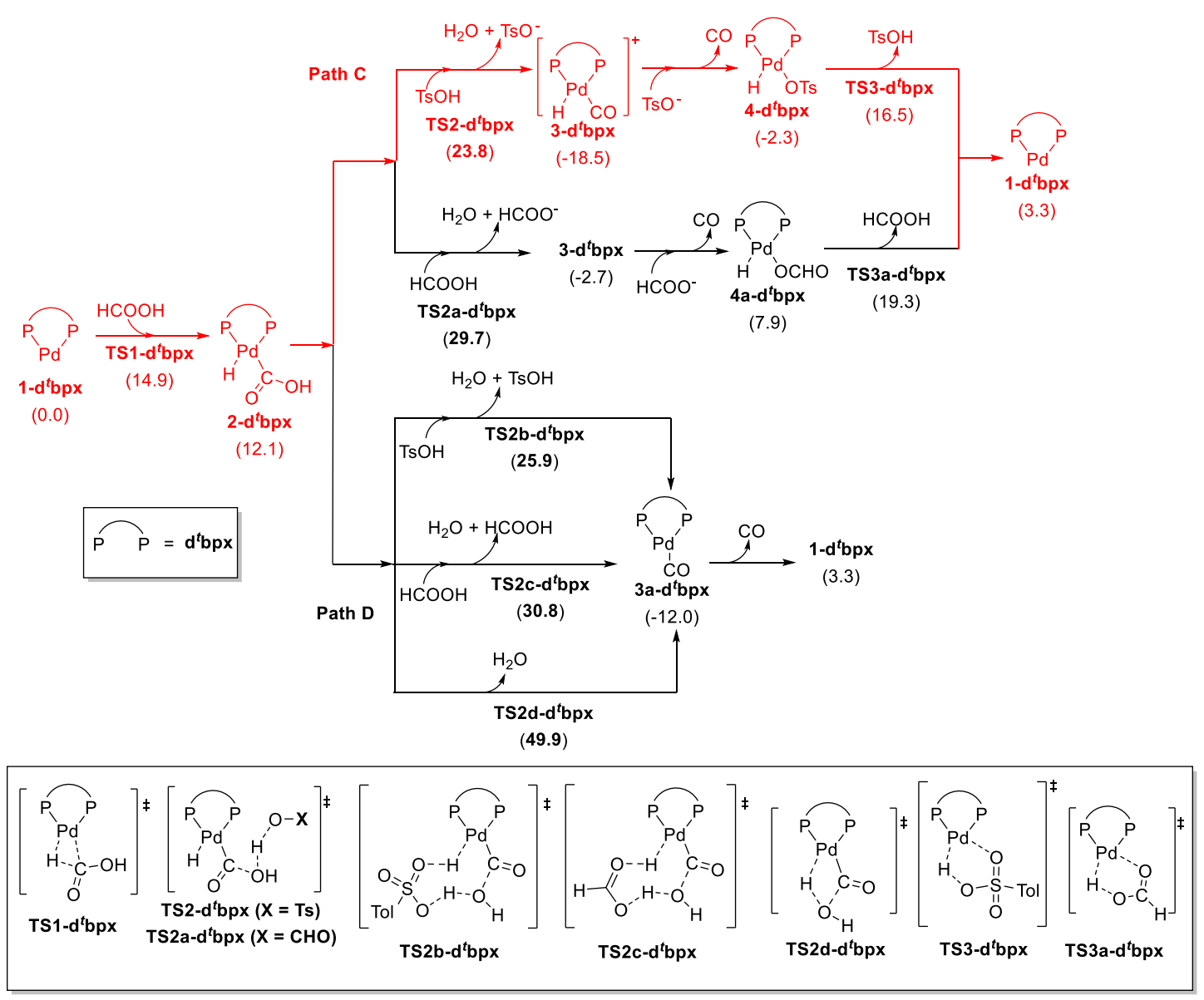

Figure 4. The dehydration of $\mathrm{HCOOH}$ catalysed by Pd-dtbpx (path $\mathbf{C}$ and $\mathbf{D}$ ).

Since the $\mathrm{C}-\mathrm{O}$ bond activation of $\mathrm{HCOOH}$ intermediate by heterogeneous catalysts is one key step of water-gas shift reaction, ${ }^{34}$ the possibility of dehydration beginning with the $\mathrm{C}-\mathrm{O}$

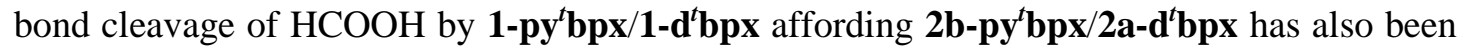
estimated. Opposite to breaking off C-H bond, the C-O bond cleavage of $\mathrm{HCOOH}$ by $\mathbf{1}-\mathbf{p y} \mathbf{y}^{\mathbf{t}} \mathbf{b p x}$ or 1-d $\mathbf{d}^{t} \mathbf{b p x}$ needs to overcome much higher energy barrier and much more endoergic (Figure

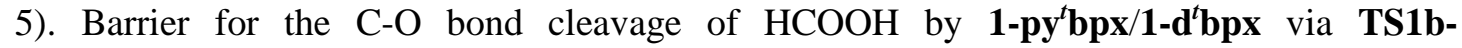

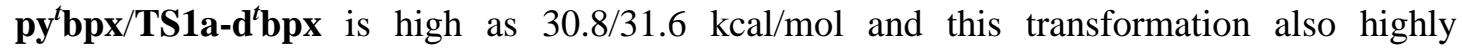
endothermic by more than $30 \mathrm{kcal} / \mathrm{mol}$. This energy pattern has clearly indicated that the $\mathrm{HCOOH}$ dehydration initialized with the activation of $\mathrm{C}-\mathrm{O}$ bond is much less probable under such relatively low reaction temperature. Thus, the subsequent intramolecular dehydration or acid-mediated intermolecular dehydration of $\mathbf{2} \mathbf{b}-\mathbf{p} \mathbf{y}^{t} \mathbf{b p x} \mathbf{2} \mathbf{2} \mathbf{a}-\mathbf{d}^{t} \mathbf{b p x}$ is not further discussed. 


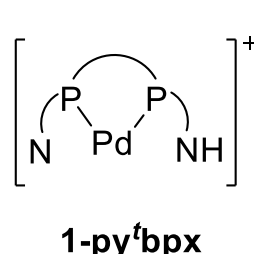

$(0.0)$

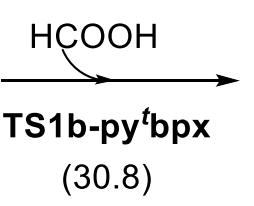

$(30.8)$

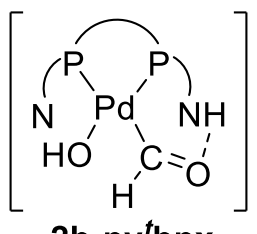

2b-pytbpx

$(30.1)$

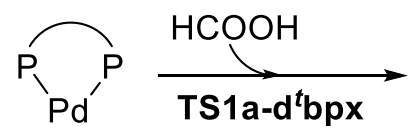

1-d ${ }^{t} \mathrm{bpx}$

$(0.0)$

(31.6)<smiles>O=C(C=[18O])[Pb]1P[P-]CCP1O</smiles>

$(30.7)$

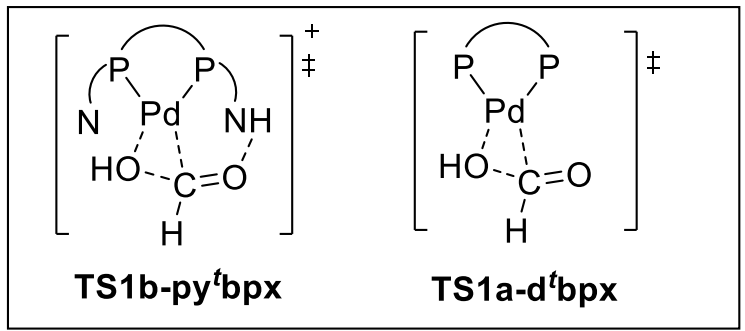

Figure 5. The C-O bond cleavage of $\mathrm{HCOOH}$ by Pd-pytbpx or Pd-d $\mathrm{d}^{t} \mathrm{bpx}$.

When using the complex of Pd-d bpx as the catalyst, the possibility of cationic palladium

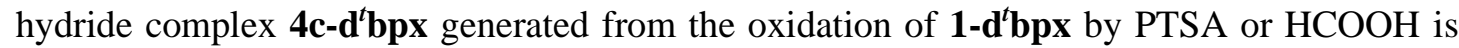

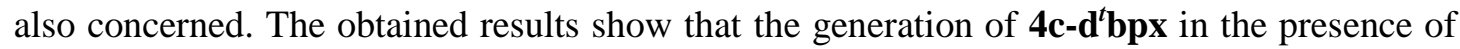
PTSA is thermodynamically and kinetically favoured (Fig. S4 in SI). In contrast, generating

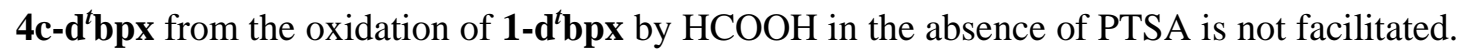
Thus, the existence of $\mathbf{4} \mathbf{c}-\mathbf{d}^{t} \mathbf{b p x}$ is only reasonable when PTSA is added. We further considered the dehydration of $\mathrm{HCOOH}$ by $\mathbf{4} \mathbf{c}-\mathbf{d}^{t} \mathbf{b p x}$. The computation result revealed that energy barrier for the dehydration of $\mathrm{HCOOH}$ by $\mathbf{4} \mathbf{c}-\mathbf{d}^{t} \mathbf{b p x}$ via $\mathbf{T S 1} \mathbf{b}-\mathbf{d}^{t} \mathbf{b p x}$ giving palladium-formyl complex 2b-d $\mathbf{d}^{t} \mathbf{b p x}$ is high as $46.1 \mathrm{kcal} / \mathrm{mol}$ (Fig. 6), although the following exothermic decomposition

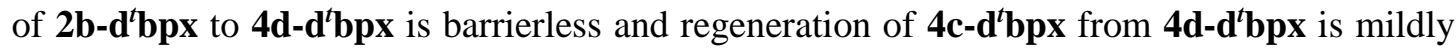
endothermic. In comparsion, the palladium hydride complex $4 \mathbf{c}-\mathbf{d}^{\mathbf{t}} \mathbf{b p x}$ undergoing deprotonation firstly to $\operatorname{Pd}(0)$ complex $1-\mathbf{d}^{t} \mathbf{b p x}$ (endothermic by $10.7 \mathrm{kcal} / \mathrm{mol}$ ), and then following the pathway A to release $\mathrm{CO}$ has the apparent barrier $34.5 \mathrm{kcal} / \mathrm{mol}$, which is still far lower than the $46.1 \mathrm{kcal} / \mathrm{mol}$. Therefore, we think that treating the $\operatorname{Pd}(0)$ complex 1-d $\mathbf{d}^{t} \mathbf{b p x}$ as the active species is more rational than the cationic palladium hydride complex $\mathbf{4} \mathbf{c}-\mathbf{d}^{t} \mathbf{b p x}$ in this reaction course. Hence, the dehydrogenative side-reaction by $\mathbf{4} \mathbf{c}-\mathbf{d}^{t} \mathbf{b p x}$ is not included in the following discussion. 
$[\overbrace{\mathrm{H}^{\mathrm{Pd}^{\prime}}}^{\mathrm{P}}]^{+}$ 4c-dtbpx $(0.0)$

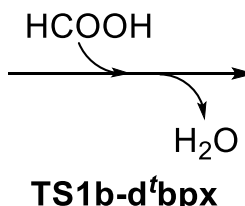

(46.1)

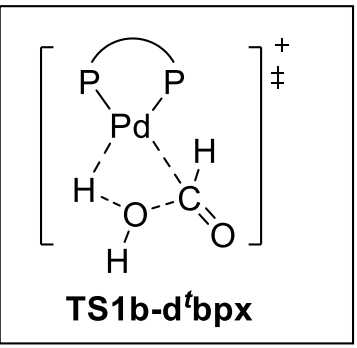

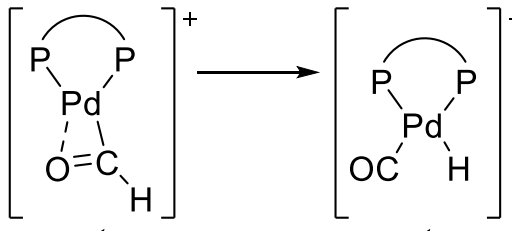

$2 b-d^{t} b p x \quad 4 d-d^{t} b p x$

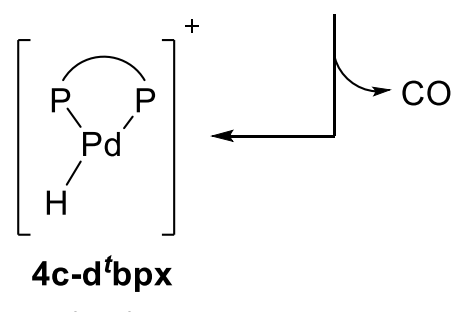

(3.3)

Figure 6. The dehydration of $\mathrm{HCOOH}$ by the coordination-unsaturated cationic palladium

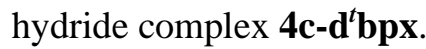

\section{HCOOH dehydrogenation by Pd-pytbpx or Pd-d ${ }^{t}$ bpx (path E, F, G and H)}

As the side reaction during the dehydration of $\mathrm{HCOOH}$, the $\mathrm{HCOOH}$ dehydrogenation to $\mathrm{H}_{2}$ and $\mathrm{CO}_{2}$ by Pd-pytbpx (Fig. 7) or Pd-dtbpx (Fig. 8) has two plausible paths. The paths start from cleaving the different bonds of $\mathrm{HCOOH}$.

Path E/G undergoes a two-step process starting from the $\mathrm{C}-\mathrm{H}$ activation of $\mathrm{HCOOH}$ by $\mathbf{1 -}$

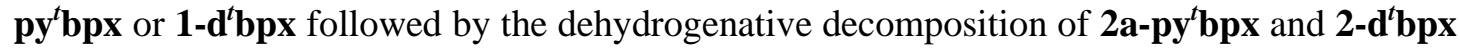
yielding $\mathrm{H}_{2}$ and $\mathrm{CO}_{2}$. Similar to the scenario in the dehydration, the dehydrogenation of 2a$\mathbf{p y}^{t} \mathbf{b p x}$ and 2-d $\mathbf{d}^{t} \mathbf{b p x}$ also have three different channels: PTSA- or HCOOH-mediated intermolecular dehydrogenation correspondingly via TS4a and TS4b, as well as the direct intramolecular dehydrogenation via TS4. As shown in Fig.7 and 8, in path $\mathbf{E} / \mathbf{G}$, the dehydrogenation step is the rate-determining step, and the acid-assisted intermolecular dehydrogenation is energetically more favoured than the direct intramolecular dehydrogenation. For Pd-py bpx, the free energy of TS4b-py $\mathbf{y}^{t} \mathbf{b p x}$ is about $2.2 \mathrm{kcal} / \mathrm{mol}$ lower than TS4-py $\mathbf{y}^{t} \mathbf{b p x}$ and TS4a-py $\mathbf{y}^{t} \mathbf{b p x}$. However, for Pd-d $\mathrm{d}^{t} \mathrm{bpx}$, the free energy of TS4a-d $\mathbf{d}^{t} \mathbf{b p x}$ is much lower than TS4-d ${ }^{t} \mathbf{b p x}$ and TS4b-d $\mathbf{d}^{t} \mathbf{b p x}$. Path $\mathbf{F} / \mathbf{H}$ undergoes a four-step process starting from breaking

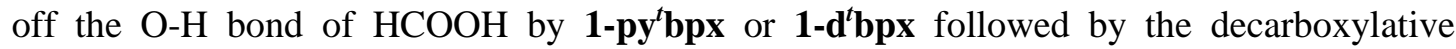

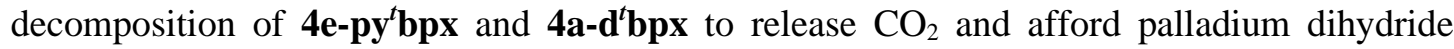
complex 5-pyt $\mathbf{b p x}$ and 5-d $\mathbf{d}^{t} \mathbf{b p x}$. Finally, $\mathrm{H}_{2}$ is produced via the reductive elimination of 5$\mathbf{p y}^{t} \mathbf{b p x}$ and 5-d $\mathbf{5} \mathbf{b p x}$. For both catalysts, the decarboxylation is the rate-determining step of path $\mathbf{F} / \mathbf{H}$. Comparing with path $\mathbf{E} / \mathbf{G}$, the apparent reaction barrier of path $\mathbf{F} / \mathbf{H}$ is much lower $(18.2 / 17.2 \mathrm{kcal} / \mathrm{mol} v s .34 .4 / 31.3 \mathrm{kcal} / \mathrm{mol})$. Thus, the dehydrogenation proceeding along path $\mathbf{F} / \mathbf{H}$ is more facile than path $\mathbf{E} / \mathbf{G}$. Noteworthily, the decarboxylation of $4 \mathbf{e}-\mathbf{p y} \mathbf{y}^{t} \mathbf{b p x}$ and $\mathbf{4 a -}$ 


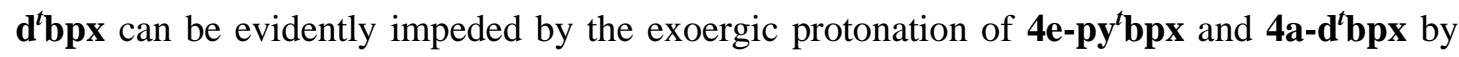

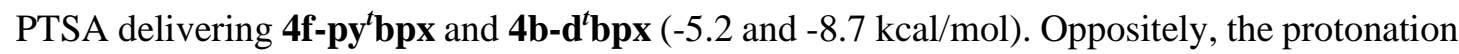

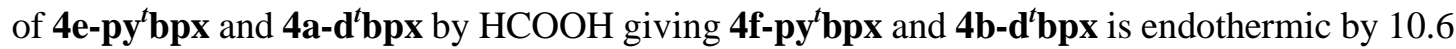
and $7.1 \mathrm{kcal} / \mathrm{mol}$. For the complex of $\mathbf{p y}^{t} \mathbf{b p x}$ ligand, with or without adding PTSA, $\mathbf{4} \mathbf{f}-\mathbf{p y} \mathbf{y}^{t} \mathbf{b p x}$

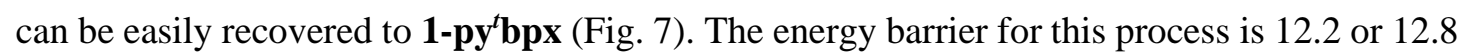
$\mathrm{kcal} / \mathrm{mol}$, much lower than the apparent reaction barrier of path $\mathbf{F}(18.2 \mathrm{kcal} / \mathrm{mol})$. In other words, the reaction course after cleaving the $\mathrm{O}-\mathrm{H}$ bond of $\mathrm{HCOOH}$ can easily fall into the proton exchange with $\mathrm{HCOOH}$ or PTSA, which leads to the prohibition of $\mathrm{H}_{2}$ releasing. For

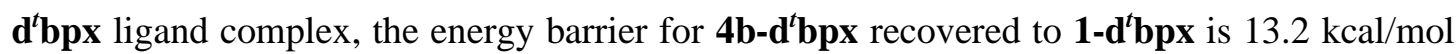
when PTSA is present, which is lower than the apparent reaction barrier of path $\mathbf{H}(17.2$ $\mathrm{kcal} / \mathrm{mol}$ ). Without PTSA, the apparent energy barrier for recovering 1-d $\mathbf{d}^{t} \mathbf{b p x}$ from $\mathbf{4} \mathbf{b}-\mathbf{d}^{t} \mathbf{b p x}$ by the proton exchange with the other $\mathrm{HCOOH}$ molecule is $16.0 \mathrm{kcal} / \mathrm{mol}$. This value is very close to the barrier of $\mathrm{H}_{2}$ releasing, which suggests that there may be a quick equilibrium between these two reaction courses. The results well explain the lower $\mathrm{H}_{2} / \mathrm{CO}_{2}$ selectivity of Pd-py ${ }^{t} \mathbf{b p x}$ complex with or without adding PTSA and Pd-d $\mathbf{d}^{t} \mathbf{b p x}$ complex with adding PTSA. 


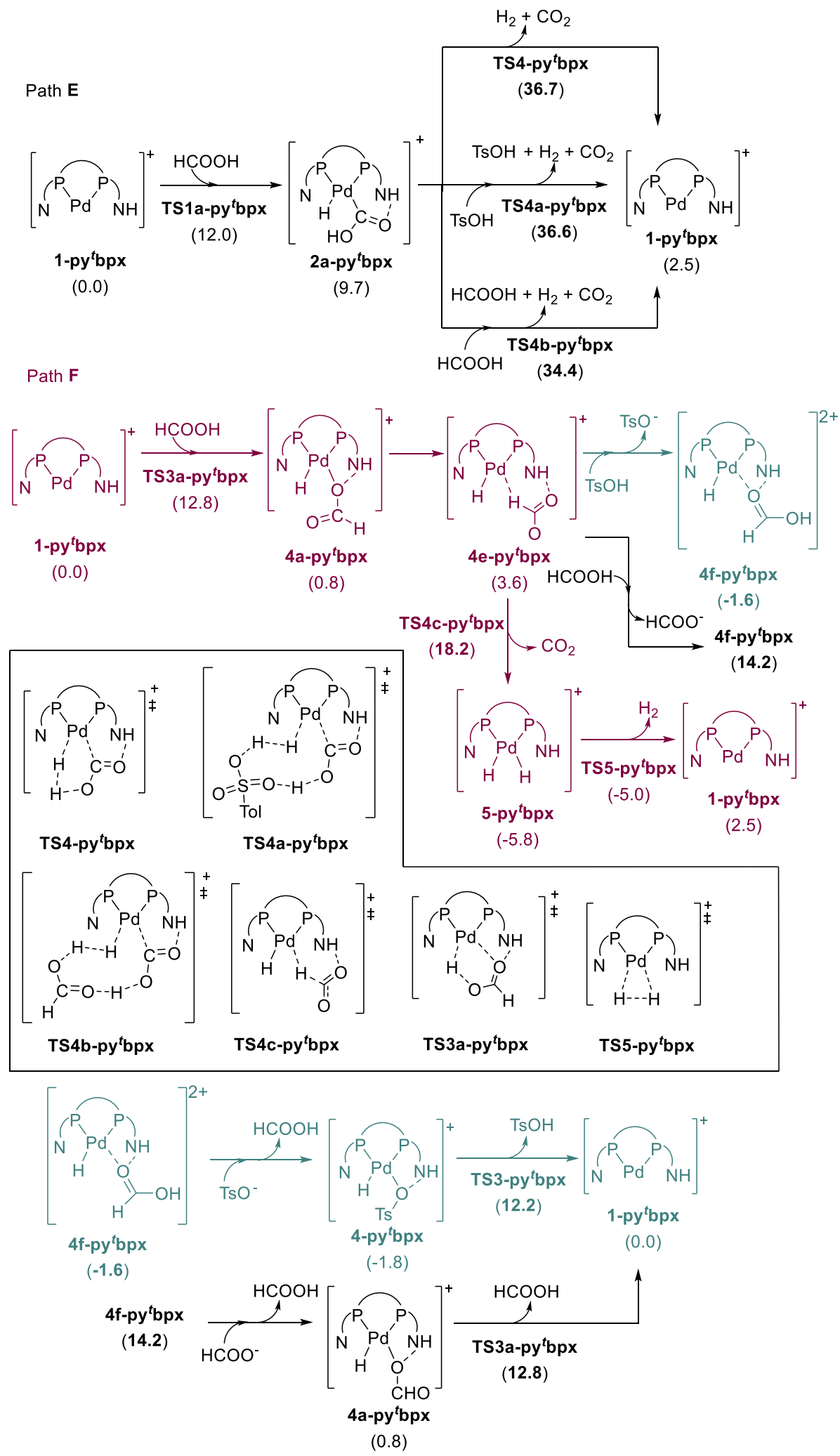

Figure 7 The dehydrogenation of $\mathrm{HCOOH}$ catalysed by Pd-py ${ }^{t}$ bpx (path $\mathbf{E}$ and $\mathbf{F}$ ) 
Path G

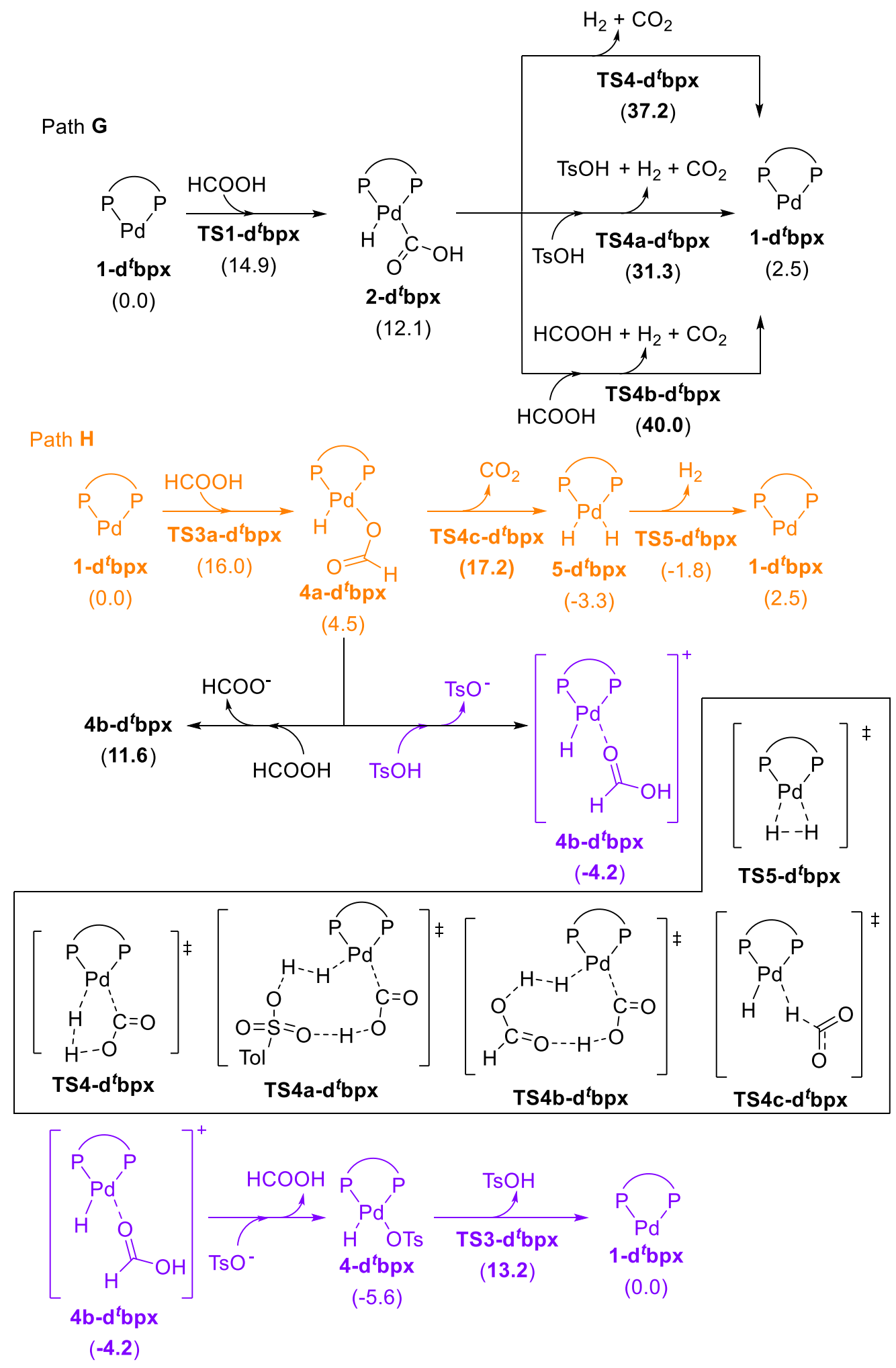

Figure 8 The dehydrogenation of $\mathrm{HCOOH}$ catalysed by Pd-d $\mathrm{d}^{t} \mathrm{bpx}$ (path $\mathbf{G}$ and $\mathbf{H}$ )

\section{Free energy comparison between different paths}

The free-energy changes for $\mathrm{CO}$ releasing and dehydrogenation pathways by Pd-py ${ }^{t} \mathrm{bpx}$ and Pd-dtbpx catalysts are compared in Scheme 1. In the absence of PTSA, the highest point of the 
free energy surface for $\mathrm{Pd}-\mathrm{py}^{t} \mathrm{bpx}$ and $\mathrm{Pd}-\mathrm{d}^{t} \mathrm{bpx}$ catalysed $\mathrm{HCOOH}$ dehydration releasing $\mathrm{CO}$ is TS2-py ${ }^{t} \mathbf{b p x}$ and TS2a-d $^{t} \mathbf{b p x}$, respectively. Obviously, Pd-py ${ }^{t}$ bpx catalyst has lower barrier for CO releasing (21.9 vs $29.7 \mathrm{kcal} / \mathrm{mol}$ ). With PTSA assisted, the regeneration of active catalyst in the reaction course of $\mathrm{HCOOH}$ dehydration is promoted by PTSA, while the dehydration step keeps still. Importantly, the free energy of TS2-py $\mathbf{y}^{t} \mathbf{b p x}$ still lower than TS2$\mathbf{d}^{t} \mathbf{b p x}$ by $1.9 \mathrm{kcal} / \mathrm{mol}(21.9 \mathrm{vs} 23.8 \mathrm{kcal} / \mathrm{mol})$, this clearly manifests that the intramolecular dehydration by the protonated "built-in base" in pytbpx ligand validly improves the catalytic efficiency of palladium catalyst in the dehydration of $\mathrm{HCOOH}$ to $\mathrm{CO}$. Moreover, the lower free

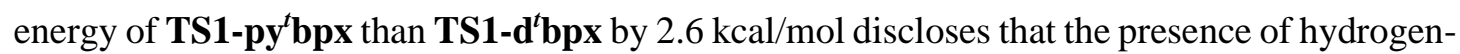
bonding interaction between $\mathrm{HCOOH}$ and the protonated py ${ }^{t} \mathrm{bpx}$ ligand significantly mitigates the energy barrier for the $\mathrm{C}-\mathrm{H}$ bond cleavage of $\mathrm{HCOOH}$ and stabilizes the intermediate 2$\mathbf{p y}^{t} \mathbf{b p x}$. The apparent reaction barrier for the dehydrogenation process by $\mathrm{Pd}-\mathrm{py} \mathrm{y}^{t} \mathrm{bpx} / \mathrm{Pd}-\mathrm{d}^{t} \mathrm{bpx}$ along path $\mathbf{F} / \mathbf{H}(18.2 / 17.2 \mathrm{kcal} / \mathrm{mol})$ is much lower than the dehydration by Pd-py ${ }^{t} \mathrm{bpx} / \mathrm{Pd}-\mathrm{d}^{t} \mathrm{bpx}$ along path $\mathbf{A} / \mathbf{C}$. However, the intermediate $4 \mathbf{e}-\mathbf{p y} \mathbf{y}^{t} \mathbf{b p x} \mathbf{4} \mathbf{4} \mathbf{a}-\mathbf{d}^{t} \mathbf{b p x}$ prefers to be transformed to the active catalyst rather than releasing $\mathrm{CO}_{2}$, which inhibits the $\mathrm{H}_{2}$ production indirectly. Compared to the scenario without PTSA, adding PTSA has slight effect on mitigating the

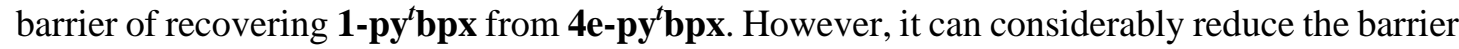
of regenerating the active catalyst $\mathbf{1}-\mathbf{d}^{t} \mathbf{b p p}$ from $\mathbf{4} \mathbf{a}^{-} \mathbf{d}^{t} \mathbf{b p x}$. That's to say, adding PTSA does not

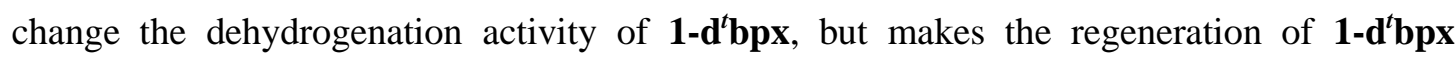
diverging from the reaction course of dehydrogenation more competitive than $\mathrm{H}_{2}$ production, and therefore inhibits the $\mathrm{H}_{2} / \mathrm{CO}_{2}$ production.

For Pd-py'bpx, PTSA improves the activity only by facilitating the CO dissociation and the regeneration of active species, while the pyridinium group contributes more to other steps. The calculated results of Pd-py ${ }^{t} \mathrm{bpx}$ catalyst well explain the high and stable chemoselectivity to CO by Pd-py'bpx under the PTSA-absent conditions. For Pd-d'bpx, adding PTSA can enhance the activity of dehydration and diminish the dehydrogenation, which significantly changes the relative selectivity. When adding PTSA promoter, the apparent $\mathrm{CO}$ releasing barrier of Pdpytbpx is lower than that of Pd-dtbpx (21.9 vs. $23.8 \mathrm{kcal} / \mathrm{mol})$, indicating the higher activity of Pd-pytbpx catalyst, which also in line with the experimental observation. It also should be mentioned that the recently reported computational investigation on producing $\mathrm{CO}$ from methyl formate intermediate by $\mathrm{Pd}-\mathrm{d}^{t} \mathrm{bpx}$ suggests a reaction path with apparent energy barrier over 30 $\mathrm{kcal} / \mathrm{mol},{ }^{35}$ which is much higher than the value obtained in this work. That report partially rationalizes the mechanism proposed in this work. It also should be mentioned that, in sharp contrast to the observed remarkable stability of Pd-pytbpx catalyst, ${ }^{25,36,37}$ the catalyst of Pd$\mathrm{d}^{t} \mathrm{bpx}$ is always prone to decompose under heating conditions, which leads to the formation of Pd nanoparticles (i.e., Pd black), ${ }^{36,38}$ despite that the presence of PTSA can more or less alleviate the decomposition of palladium complex. Such distinction on stability is more obvious under the water-contained acidic conditions. ${ }^{36,38}$ Since palladium nanoparticle has high activity and 
selectivity towards dehydrogenation of $\mathrm{HCOOH}$ even under low temperature, ${ }^{39-42}$ we therefore infer that the dehydrogenation during the whole decomposing process of $\mathrm{HCOOH}$ catalysed by $\mathrm{Pd}-\mathrm{d}^{t} \mathrm{bpx}$, is probably partially contributed by the palladium nanoparticle resulted from the degradation of Pd-dtbpx catalyst. Furthermore, the catalytic activity of Pd nanoparticles is susceptible to the particle size, surface structure, oxidation state of $\mathrm{Pd}$ atom and $\mathrm{pH}$ value of reaction medium. ${ }^{43-45}$ Thus, the Pd-dtbpx catalyst system is far more complicated and cannot be simply explained by only considering the single catalyst that studied in this report.

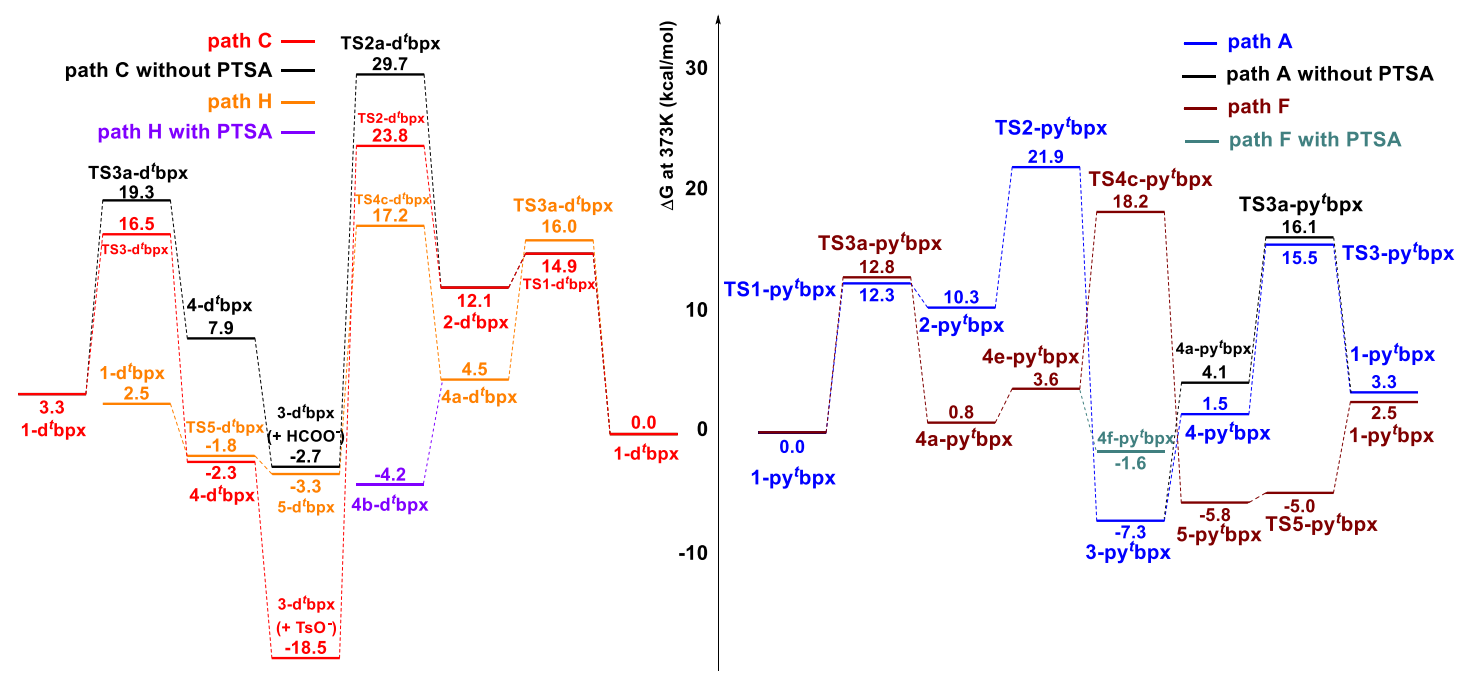

Scheme 1 The solvated free-energy changes of advantaged CO releasing or dehydrogenation pathways for Pd-py ${ }^{t} \mathrm{bpx}$ and Pd-d bpx catalyst at $373 \mathrm{~K}$ with or without PTSA promoter (the reaction course along path $\mathbf{F} / \mathbf{H}$ with PTSA after $\mathbf{4 f -}-\mathbf{p y}^{t} \mathbf{b p x} \mathbf{p} / \mathbf{4} \mathbf{b}-\mathbf{d}^{t} \mathbf{b p x}$ was omitted for the clarity of presentation).

\section{Path A and F of Pd-py ${ }^{t} b p x$ in the presence of excess PTSA}

Since the molar amount of PTSA is excessive to py bpx ligand in the experimental report and

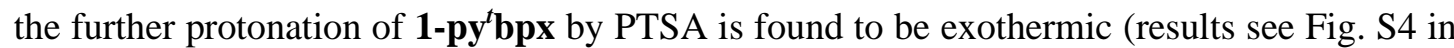
SI), the scenario of dehydration and dehydrogenation along path $\mathbf{A}$ and $\mathbf{F}$ by $\mathbf{1 -}\left(\mathbf{p y}^{\mathbf{t}} \mathbf{b p x} \mathbf{\mathbf { p }}-\mathbf{H}\right)$, the dicationic palladium catalyst of bis-protonated pytbpx ligand, was also investigated and compared with the paths by 1-py $\mathbf{y}^{\mathbf{t}} \mathbf{b p x}$. Fig. 9 summarizes the overall process of path $\mathbf{A}$ and $\mathbf{F}$ by 1-(py $\left.\mathbf{y}^{t} \mathbf{b p x}-\mathbf{H}\right)$. The apparent barriers of $\mathrm{HCOOH}$ dehydration and dehydrogenation respectively along path $\mathbf{A}$ and $\mathbf{F}$ by $\mathbf{1}-\left(\mathbf{p y y}^{t} \mathbf{b p x}-\mathbf{H}\right)$ are elevated to 27.1 and $28.9 \mathrm{kcal} / \mathrm{mol}$. The

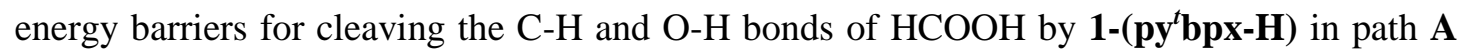
and $\mathbf{F}$ also go up to 17.1 and $17.4 \mathrm{kcal} / \mathrm{mol}$, respectively. Moreover, owing to the presence of two hydrogen-bonding interaction between the coordinated formate anion and the bisprotonated py ${ }^{t} \mathbf{b p x}$ ligand, the transformation from $\mathbf{4 a -}-\left(\mathbf{p y} \mathbf{y}^{t} \mathbf{b p x}-\mathbf{H}\right)$ to $\mathbf{4 d -}-\left(\mathbf{p} \mathbf{y}^{t} \mathbf{b p x}-\mathbf{H}\right)$ is far more endothermic than the corresponding transformation from $4 \mathbf{a}-\mathbf{p y} \mathbf{y}^{t} \mathbf{b p x}$ to $4 \mathbf{4}-\mathbf{p y} \mathbf{y}^{t} \mathbf{b p x}$. The presence of PTSA also inhibits the decarboxylation of $\mathbf{4 d}-\left(\mathbf{p y} \mathbf{y}^{t} \mathbf{b p x}-\mathbf{H}\right)$ by protonating $4 \mathbf{d}$ - 


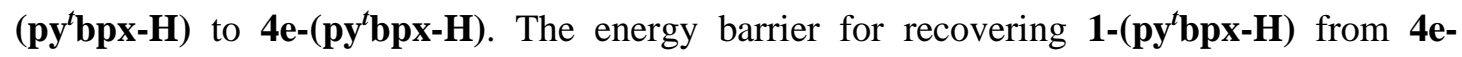
$\left(\mathbf{p y}^{t} \mathbf{b p x} \mathbf{b}-\mathbf{H}\right)$ is lower than the apparent reaction barrier of path $\mathbf{F}$. In short, the further protonation of 1-py $\mathbf{y}^{t} \mathbf{b p x}$ by PTSA reduces the activity of Pd-py ${ }^{t} b p x$ catalyst on both dehydration and dehydrogenation. Meanwhile, the apparent barrier of path $\mathbf{F}$ exceeds over that of path $\mathbf{A}$, which makes the chemoselectivity of catalyst more favoured to $\mathrm{HCOOH}$ dehydration. This is also in line with the experimental report. ${ }^{25}$ 

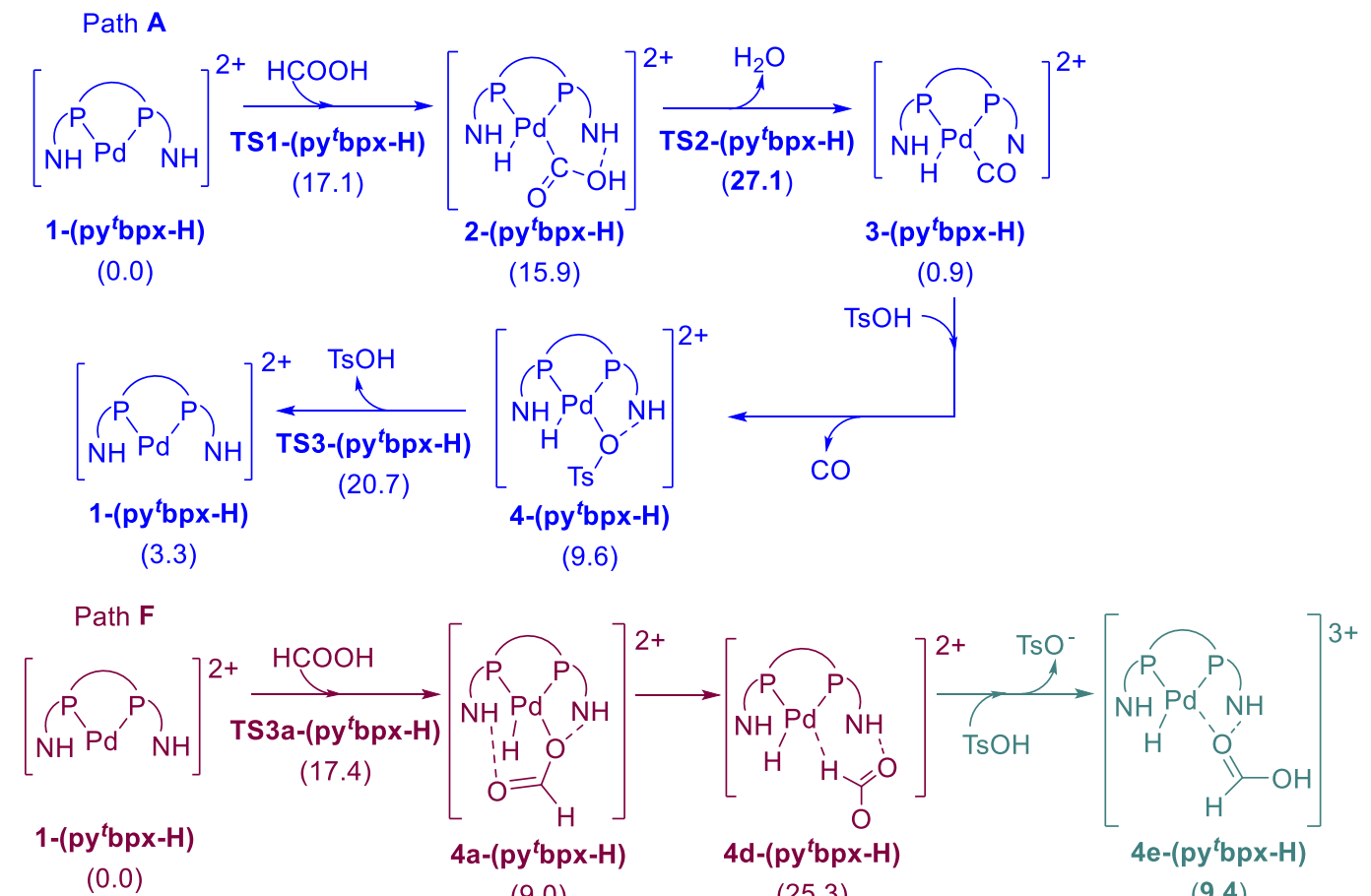

(25.3)

$(9.4)$

$4 e-\left(p{ }^{t} b p x-H\right)$

(25.1)

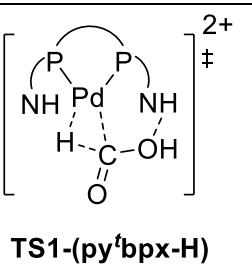

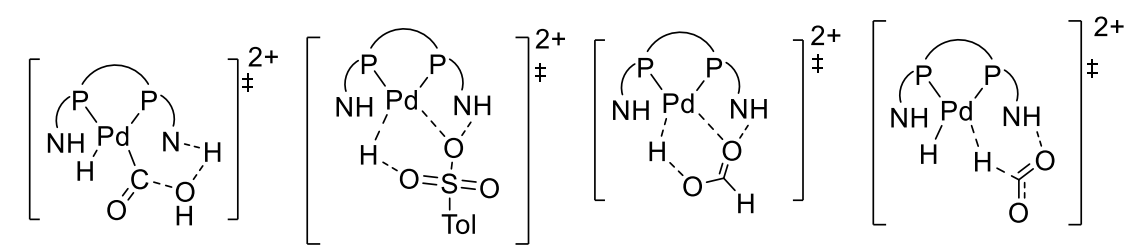

TS2-(pytbpx-H) TS3-(py $\left.{ }^{t} b p x-H\right) \quad$ TS3a-(py $\left.{ }^{t} b p x-H\right) \quad$ TS4c-(py $\left.{ }^{t} b p x-H\right) \quad$ TS5-(py $\left.{ }^{t} b p x-H\right)$

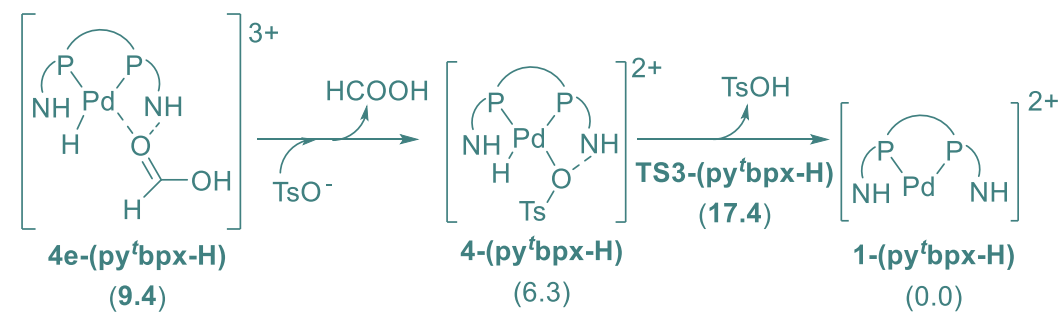

Figure 9. Free-energy changes for path $\mathbf{A}$ and $\mathbf{F}$ by the bis-protonated Pd-pytbpx catalyst.

Preliminary survey and prediction of the structure-activity relationship between ligand and PTSA-mediated HCOOH dehydration 
The preliminary survey and prediction on the relationship between the structure of phosphine ligand based on the skeleton of $\mathrm{py}^{\mathrm{t}} \mathrm{bpx}$ and the activity of PTSA-mediated HCOOH dehydration was also conducted. Since Pd-pyadbpx catalyst exhibits slightly higher activity than Pd-py ${ }^{t} b p x$ in the PTSA-promoted $\mathrm{HCOOH}$ dehydration (Fig. 1), the reaction proceeding along path $\mathbf{A}$ catalysed by Pd-pyadbpx was computed to reveal the effect of more sterically hindered 1adamantyl group on each elementary step. Fig. 10 demonstrated that compared with the corresponding transition states in path $\mathbf{A}$ by $\mathrm{Pd}-\mathrm{py}^{t} \mathrm{bpx}$, introducing 1-admantyl group into the pyridyl-substituted bidentate phosphine ligand leads to the drop on the free energy of TS1 and TS2 as well as the mitigation of apparent energy barrier (20.8 vs. $21.9 \mathrm{kcal} / \mathrm{mol}$ ) for overall process. Meanwhile, the free energy of TS3 for regenerating 1-pyadbpx is elevated. The obtained overall energy profile for PTSA-mediated $\mathrm{HCOOH}$ dehydration by Pd-pyadbpx is in line with the aforementioned experimental observation.

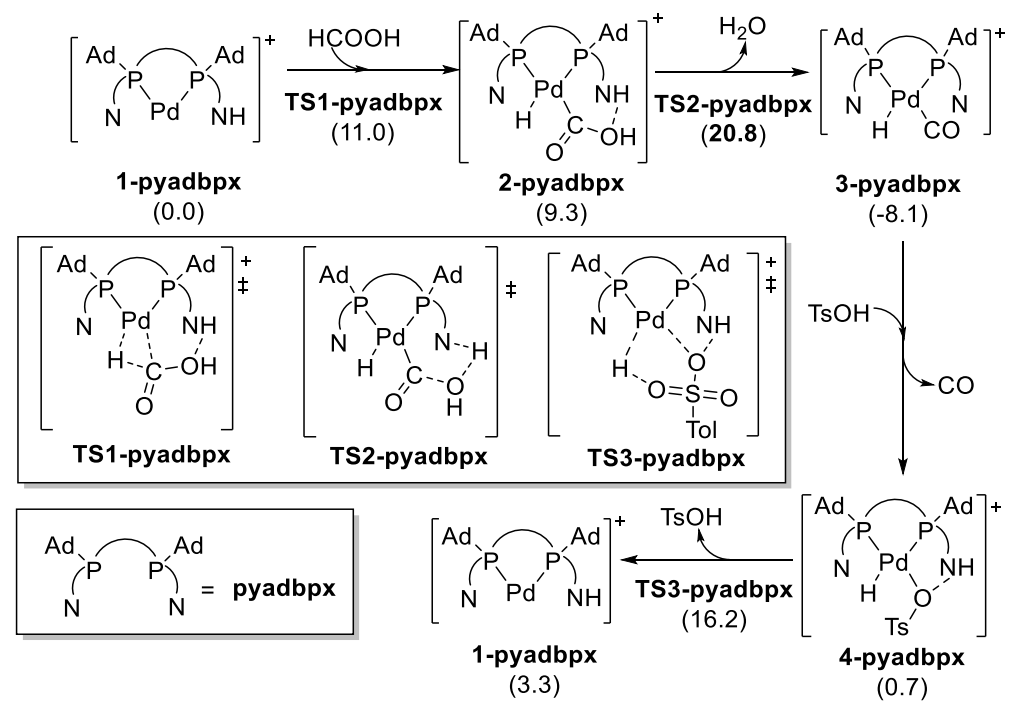

Figure 10. Free-energy changes for $\mathrm{HCOOH}$ dehydration by Pd-pyadbpx catalyst along path A

Since the intramolecular dehydration of intermediate $\mathbf{2}$ is the rate-determining step of path $\mathbf{A}$ for Pd-py ${ }^{t} \mathrm{bpx}$ and in order to foresee whether the proton transfer in this step is affected by the basicity of pyridyl group, the effect of substituent at the 4-position of pyridyl rings on the dehydrative activity of palladium catalyst was predicted by computing the variation of TS2(py $\left.\mathbf{y}^{\mathbf{t}} \mathbf{b} \mathbf{p}-\mathbf{R}\right)$ on the free-energy surface. The outcomes displayed in Fig. 11 showed that introducing electron-donating substituent, such as methyl or methoxy group, at the paraposition of pyridyl group would result to the rising of barrier. While, introducing electronwithdrawing chloric atom can boost the proton transfer and thus reduce barrier. This energy pattern predicts that the analogues of py ${ }^{t} \mathrm{bpx}$ ligand bearing less-basic 4-substituted pyridyl group may exhibited higher dehydration activity. 


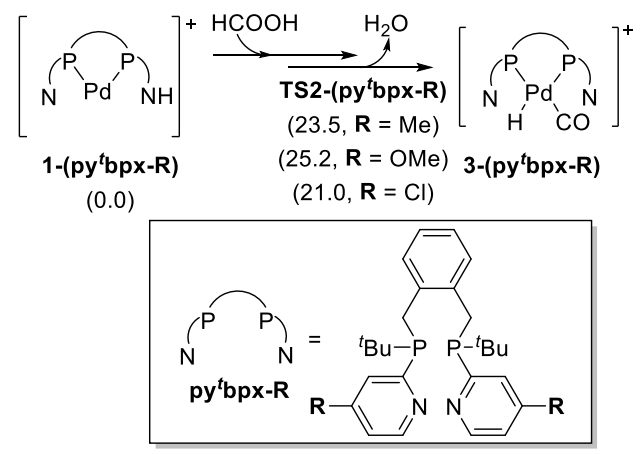

Figure 11 The free-energy variation of TS2-(py $\left.\mathbf{y}^{t} \mathbf{b p x}-\mathbf{R}\right)$ with the change of substituent at the 4-position of pyridine ring in $\mathrm{py}^{t} \mathrm{bpx}$ ligand.

\section{Conclusions}

In summary, the DFT-based computational survey unveils the role of "built-in base" and strong para-toluenesulfonic acid promoter in the dehydrative decomposition of $\mathrm{HCOOH}$ to $\mathrm{CO}$ catalysed by Pd-py bpx. The basic pyridyl group installed in the ligand of py ${ }^{t} \mathrm{bpx}$ changes the mode of intermolecular dehydration aid by the acid to the mode of intramolecular dehydration facilitated by the pyridinium group, which turns down the apparent activation energy of reaction. Excessive PTSA acid can lead to the bis-protonation of py bpx ligand, thereby further changes the selectivity of the product. Adding PTSA promoter, the activity of Pd-d $\mathrm{d}^{\mathrm{b} p x}$ catalyst on $\mathrm{HCOOH}$ dehydration is enhanced, and the $\mathrm{CO}$ selectivity is also improved by inhibiting the $\mathrm{H}_{2}$ production indirectly through transformaing the intermediate back to the active catalyst. Based on the hereby proposed mechanism, the positive effect of electron-withdrawing substituent at the para-position of pyridyl rings is predicted.

\section{Author Contributions}

C. S.: writing original draft, investigation, formal analysis, methodology, visualization; X. T.: review \& editing conceptualization, methodology, project administration; Z. W.: review \& editing; K. D.: conceptualization, funding acquisition. All the authors discussed the results and contributed to the writing of the manuscript.

\section{Conflicts of interest}

There are no conflicts to declare.

\section{Acknowledgements}

C.S. and X.T. thank the financial supports from the National Natural Science Foundation of China (No. 21903049 for X.T., 21802151 for C.S.) Part of the calculations were performed at the Shanghai Supercomputer Centre and the Supercomputing Centre of Shanxi University. 


\section{Notes and references}

1 R. Sang, Y. Hu, R. Razzaq, R. Jackstell, R. Franke, M. Beller, Org. Chem. Front., 2021, 8, 799-811.

2 Z. Yin, J.-X. Xu, X.-F. Wu, ACS Catal., 2020, 10, 6510-6531.

3 J.-B. Peng, F.-P. Wu, X.-F. Wu, Chem. Rev., 2019, 119, 2090-2127.

4 X.-F. Wu, X. Fang, L. Wu, R. Jackstell, H. Neumann, M. Beller, Acc. Chem. Res., 2014, 47, 1041-105.

5 X.-F. Wu, H. Neumann, M. Beller, Chem. Rev., 2013, 113, 1-35.

6 J. Pospech, I. Fleischer, R. Franke, S. Buchholz, M. Beller, Angew. Chem. Int. Ed., 2013, 52, 2852-2872.

7 A. Brennführer, H. Neumann, M. Beller, Angew. Chem. Int. Ed. Engl., 2009, 48, 411433.

8 S. D. Friis, A. T. Lindhardt, T. Skrydstrup, Acc. Chem. Res. 2016, 49, 594-605.

9 Z. Chen, L.-C. Wang, X.-F. Wu, Chem. Commun., 2020, 56, 6016-6030.

10 L. Wang, W. Sun, C. Liu, Chin. J. Chem., 2018, 36, 353-362.

11 H. Konishi, Chem. Pharm. Bull. 2018, 66, 1-19.

12 P. Gautama, B. M. Bhanage, Catal. Sci. Technol., 2015, 5, 4663-4702.

13 L. Wu, Q. Liu, R. Jackstell, M. Beller, Angew. Chem. Int. Ed., 2014, 53, 6310-6320.

14 L. R. Odell, F. Russo, M. Larhed, Synlett, 2012, 685-698.

15 T. Morimoto, K. Kakiuchi, Angew. Chem. Int. Ed., 2004, 43, 5580-5588.

16 F. Ramirez-Vega, P. Laurent, J.-C. Clément, H. des Abbayes J. Mol. Catal. A: Chem., 1995, 96, 15-20.

17 T. Ueda, H. Konishi, K. Manabe, Angew. Chem. Int. Ed., 2013, 52, 8611-8615.

18 L.-B. Jiang, X. Qi, X.-F. Wu, Tetrahedron Lett., 2016, 57, 3368-3370.

19 (a) J. S. Morgan, J. Chem. Soc., Trans., 1916, 109, 274-283; (b) R. E. DeRight, J. Am.

Chem. Soc., 1933, 55, 4761-4764; (c) G. Ciuhandu, A. Dumitreanu, Z. Simon, J. Prakt. Chem., 1976, 318, 202-206.

20 J. Guo, C. K. Yin, D. L. Zhong, Y. L. Wang, T. Qi, G. H. Liu, L. T. Shen, Q. S. Zhou, Z. H. Peng, H. Yao, X. B. Li, ChemSusChem, 2021, 14, 2655-2681.

21 J. Hou, J.-H. Xie Q.-L. Zhou, Angew. Chem. Int. Ed., 2015, 54, 6302-6305.

22 J. Dai, W. Ren, W. Chang, P. Zhang, Y. Shi, Org. Chem. Front., 2016, 3, 1131-1136.

23 W. Liu, W. Ren, J. Li, Y. Shi, W. Chang, Y. Shi, Org. Lett., 2017, 19, 1748-1751.

24 W. Ren, J. Chu, F. Sun, Y. Shi, Org. Lett., 2019, 21, 5967-5970.

25 R. Sang, P. Kucmierczyk, K. Dong, R. Franke, H. Neumann, R. Jackstell, M. Beller, J. Am. Chem. Soc., 2018, 140, 5217-5223.

26 K. Dong, R. Sang, Z. Wei, J. Liu, A. Spannenberg, H. Jiao, R. Franke, M. Beller, Chem. Sci., 2018, 9, 2510-2516. 
27 J. Liu, Z. Wei, J. Yang, Y. Ge, D. Wei, R. Jackstell, H. Jiao, M. Beller, ACS Catal., 2020, 10, 12167-12181.

28 M. J. Frisch, G. W. Trucks, H. B. Schlegel, G. E. Scuseria, M. A. Robb, J. R. Cheeseman, G. Scalmani, V. Barone, G. A. Petersson, H. Nakatsuji, X. Li, M. Caricato, A. V. Marenich, J. Bloino, B. G. Janesko, R. Gomperts, B. Mennucci, H. P. Hratchian, J. V. Ortiz, A. F. Izmaylov, J. L. Sonnenberg, D. Williams-Young, F. Ding, F. Lipparini, F. Egidi, J. Goings, B. Peng, A. Petrone, T. Henderson, D. Ranasinghe, V. G. Zakrzewski, J. Gao, N. Rega, G. Zheng, W. Liang, M. Hada, M. Ehara, K. Toyota, R. Fukuda, J. Hasegawa, M. Ishida, T. Nakajima, Y. Honda, O. Kitao, H. Nakai, T. Vreven, K. Throssell, J. A. Montgomery, Jr., J. E. Peralta, F. Ogliaro, M. J. Bearpark, J. J. Heyd, E. N. Brothers, K. N. Kudin, V. N. Staroverov, T. A. Keith, R. Kobayashi, J. Norm,, K. Raghavachari, A. P. Rendell, J. C. Burant, S. S. Iyengar, J. Tomasi, M. Cossi, J. M. Millam, M. Klene, C. Adamo, R. Cammi, J. W. Ochterski, R. L. Martin, K. Morokuma, O. Farkas, J. B. Foresman, D. J. Fox, Gaussian 16., Revision A.03.03, Gaussian, Inc., Wallingford C.T, 2016.

29 Y. Zhao, D. G. Truhlar, Theor. Chem. Account., 2008, 120, 215-241.

30 Y. Zhao, D. G. Truhlar, Acc. Chem. Res., 2008, 41, 157-167

31 F. Weigend, R. Ahlrichs, Phys. Chem. Chem. Phys. 2005, 7, 3297-3305.

32 A. V. Marenich, C. J. Cramer, D. G. Truhlar, J. Phys. Chem. B 2009, 113, 6378-6396.

33 T. Lu, Q. Chen, Comput. Theor. Chem., 2021, 1200, 113249.

34 L. C. Grabow, M. Mavrikakis, ACS Catal. 2011, 1, 365-384

35 R. Geitner, A. Gurinov, T. Huang, S. Kupfer, S. Grafe, B. M. Weckhuysen, Angew. Chem. Int. Ed., 2021, 60, 3422-3427

36 R. Sang, P. Kucmierczyk, R. Dühren, R. Razzaq, K. Dong, J. Liu, R. Franke, R. Jackstell, M. Beller, Angew. Chem. Int. Ed. 2019, 58, 14365-14373

37 K. Dong, R. Sang, J. Liu, R. Razzaq, R. Franke, R. Jackstell , M. Beller, Angew. Chem., Int. Ed. 2017, 56, 6203-6207.

38 J. Vondran, M. R. L. Furst, G. R. Eastham, Thomas Seidensticker, D. J. Cole-Hamilton, Chem. Rev., 2021, 121, 6610-6653

39 Q.-Y. Bi, J.-D. Lin, Y.-M. Liu, H.-Y. He, F.-Q. Huang, Y. Cao, Angew. Chem. Int. Ed., 2016, 55, 11849-11853.

40 H. J. Young, M. Chung, App. Catal. B, Environ., 2017, 210, 212-222.

41 Q. Wang, N. Tsumori, M. Kitta , Q. Xu, ACS Catal. 2018, 8, 12, 12041-12045.

42 L. Di, J. Zhang, M. Craven, Y. Wang, H. Wang, X. Zhang, X. Tu, Catal. Sci. Technol., 2020, 10, 6129-6138.

43 S. Jones, S. M. Fairclough, M. Gordon-Brown, W. Zheng, A. Kolpin, B. Pang, W. C. H. Kuo, J. M. Smith, S. C. E. Tsang, Chem. Commun., 2015, 51, 46-49.

44 S. Zhang, B. Jiang, K. Jiang, W.-B. Cai, ACS Appl. Mater. Interfaces, 2017, 9, 2467824687. 
45 Y. Kim, D. H. Kim, App. Catal. B: Environ., 2019, 244, 684-693. 